\title{
8
}
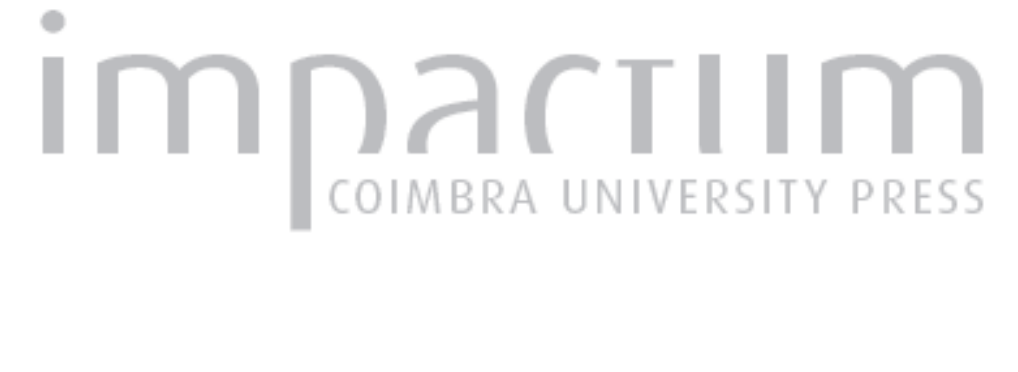

\section{Implementação da Agenda Local 21 em Portugal: desafios para a sustentabilidade Local}

Autor(es): $\quad$ Fidélis, Teresa; Pires, Sara Moreno

\section{Publicado por: CEDOUA}

URL persistente:

URI:http://hdl.handle.net/10316.2/8824

DOI: http://dx.doi.org/10.14195/2182-2387_21_3

Accessed : $\quad$ 26-Apr-2023 10:57:00

A navegação consulta e descarregamento dos títulos inseridos nas Bibliotecas Digitais UC Digitalis, UC Pombalina e UC Impactum, pressupõem a aceitação plena e sem reservas dos Termos e Condições de Uso destas Bibliotecas Digitais, disponíveis em https://digitalis.uc.pt/pt-pt/termos.

Conforme exposto nos referidos Termos e Condições de Uso, o descarregamento de títulos de acesso restrito requer uma licença válida de autorização devendo o utilizador aceder ao(s) documento(s) a partir de um endereço de IP da instituição detentora da supramencionada licença.

Ao utilizador é apenas permitido o descarregamento para uso pessoal, pelo que o emprego do(s) título(s) descarregado(s) para outro fim, designadamente comercial, carece de autorização do respetivo autor ou editor da obra.

Na medida em que todas as obras da UC Digitalis se encontram protegidas pelo Código do Direito de Autor e Direitos Conexos e demais legislação aplicável, toda a cópia, parcial ou total, deste documento, nos casos em que é legalmente admitida, deverá conter ou fazer-se acompanhar por este aviso.

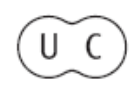




\section{RerCEDöUA}

N. ${ }^{21}$ _Ano XI_1. 08

\section{) Doutrina}

Direitos Humanos, Ambiente e Sustentabilidade

Klaus Bosselmann

O principio da conciliação : fumo a um controlo da "sustentabilidade"?

Chantal Cans

Implementaçäo da Agenda Local 2l em Portugal:

Desafios para a Sustentabilidade Local
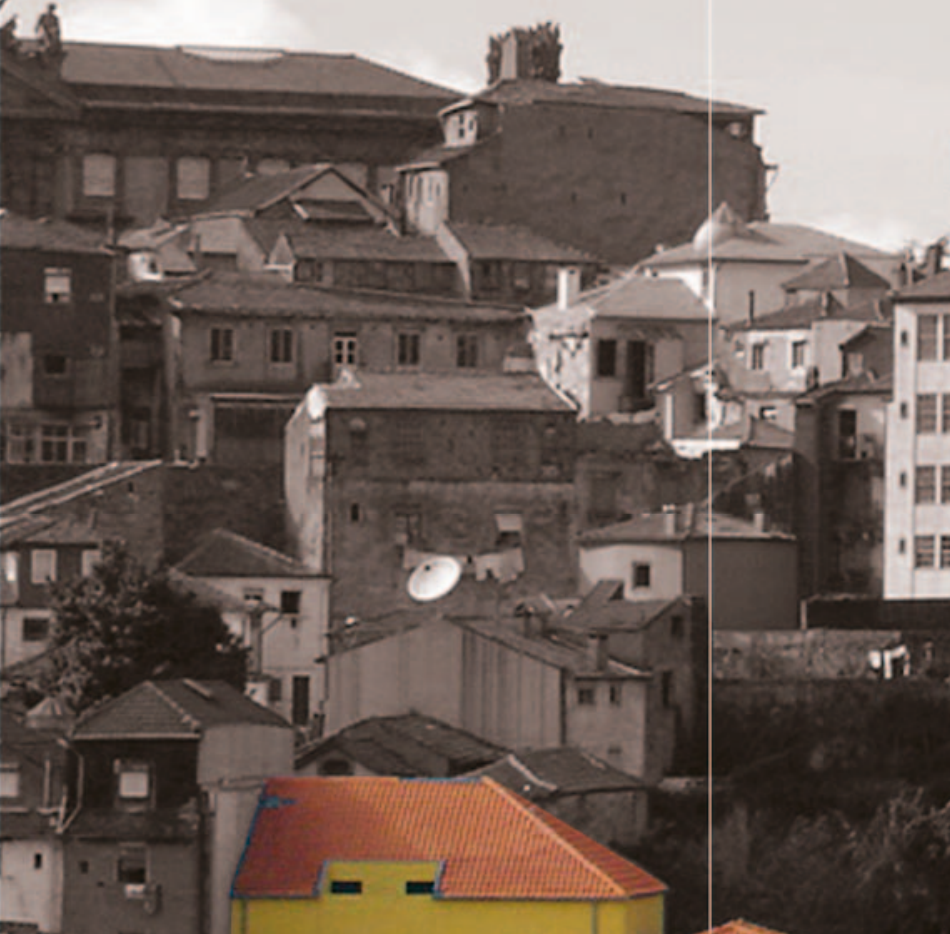

Teresa Fidélis

Sara Moreno Pires

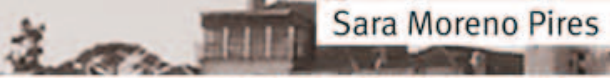

O Regime Jurídico Excepcional da Reabilitiaçäo Urbana [Decreto Lei 104/2004, de 7 de Maio]

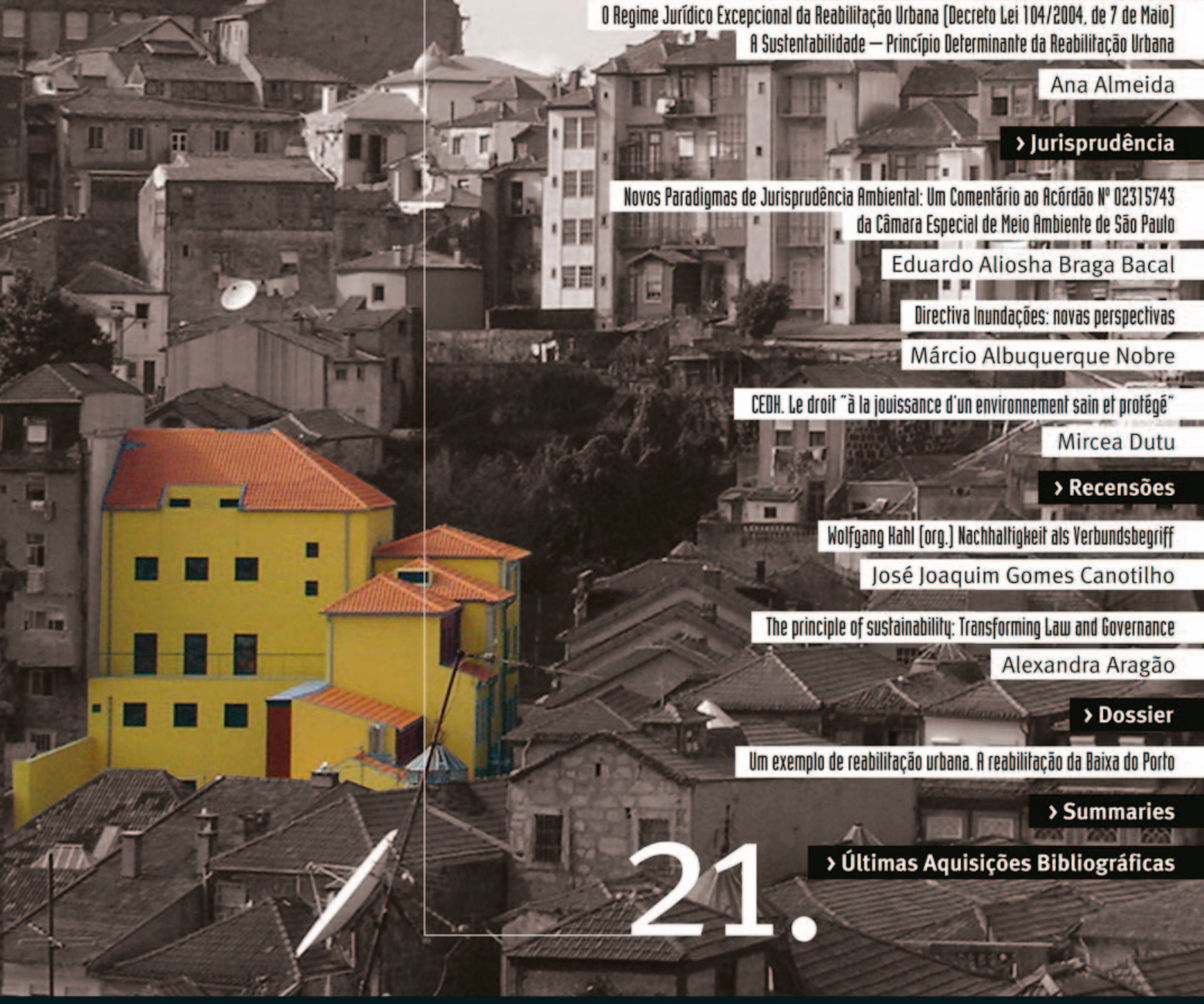

Revista do Centro de Estudos de Direito do Ordenamento, do Urbanismo e do Ambiente Urbanism, Territorial Order and Environment Studies Center Law Review 


\section{Implementação da Agenda Local 21 em Portugal: Desafios para a Sustentabilidade Local ${ }^{*}$}

\begin{abstract}
Este artigo pretende analisar a forma como a implementação da Agenda Local 21 (AL21) em Portugal está a contribuir para uma governação local apoiada num modelo de desenvolvimento sustentável. Partindo de uma visão teórica sobre a governação para o desenvolvimento sustentável - centrada na análise dos seus principais valores e desafios e em perceber o potencial da AL21 para a sua prossecução -, este artigo desenvolve uma reflexão crítica sobre o tema a partir dos resultados mais relevantes obtidos através da implementação de um questionário dirigido aos municípios portugueses. 0 artigo, pretende expor algumas das principais potencialidades, limitações e desafios da realidade local portuguesa, em particular no que respeita à implementação da Agenda Local 21, e em geral, no que respeita à governação local tendo em vista modelos de governação mais coerentes com o conceito de desenvolvimento sustentável.
\end{abstract}

\section{O Debate da Governação para o Desenvolvimento Sustentável}

Designadamente na língua inglesa, o conceito de governação (governance) referia-se tradicionalmente à actividade dos governos e a como os políticos eleitos exerciam o poder, mas a reemergência do conceito a partir dos anos 80 'abriu-o' muito para além do limite semântico de "governo". Esta mutação linguística no uso de "governação" ao longo das duas últimas décadas, aparece como uma resposta às transformações de um mundo caracterizado, entre outros aspectos, por uma globalização inexorável, um processo de complexificação das relações entre o Estado e a sociedade civil, e uma fragmentação crescente de decisões (Hirst 2000, in Kjaer 2004). Nas palavras de Rhodes: "o Estado foi esvaziado superiormente (por ex. através da interdependência internacional), inferiormente (através

\footnotetext{
* O presente artigo baseia-se na versão publicada em Fidélis, T. e Pires, S. M. (2009) 'Surrender or resistance to the implementation of Local Agenda 21 in Portugal: the challenges of local governance for sustainable development', Journal of Environmental Planning and Management, 52(4), pp. 497-518.
} 


\section{RerCEDőUA}

Doutrina

da mercantilização e da criação de redes), e lateralmente (por agências)" (Rhodes 2003, p. 69), mas continua a reter, todavia, um papel fundamental. Bache e Flinders (2004) resumem bem estas mudanças institucionais: (1) um aumento da participação de actores nãoestatais na tomada de decisão nos vários níveis territoriais; (2) a crescente sobreposição de redes, com as inerentes dificuldades de identificação de níveis territoriais distintos na tomada de decisão; (3) a transformação do papel do Estado, onde se tem vindo a desenvolver um conjunto de novas estratégias de coordenação, orientação e estabelecimento de redes para proteger e, em alguns casos mesmo aumentar, a autoridade Estatal; por fim, (4) um ajuste da natureza da responsabilização democrática e a necessidade de a rever, ou pelo menos de a repensar.

Estas mudanças apontam para a própria essência da governação para o desenvolvimento sustentável ${ }^{1}$. Segundo Lafferty (2004), a governação assente em preocupações de desenvolvimento sustentável implica uma integração horizontal e vertical dos valores e princípios fundamentais da sustentabilidade na actividade governamental (algo extremamente exigente em termos de coordenação) e suscita um encontrar de formas efectivas para mobilizar e envolver a sociedade civil (desafiando a natureza da responsabilização democrática) na formulação e implementação de políticas sectoriais (em redes sobrepostas) (Lafferty 2004).

De uma forma geral, um sistema de governação pode ser considerado eficaz, se conseguir assegurar que as suas políticas são desenvolvidas e implementadas de uma forma consistente e efectiva através dos limites institucionais, apontando para fins "desejáveis", como a sustentabilidade, e afastando-se de fins "indesejáveis", como a insustentabilidade. As tensões entre os valores fundamentais de uma "boa" governação - entre os quais, a legitimidade, eficiência, democracia e a responsabilização - estão sempre presentes, e, no que diz respeito ao desenvolvimento sustentável, os trade-offs entre os mesmos são particularmente vibrantes.

O primeiro grande dilema relaciona-se com o garantir da legitimidade das políticas públicas num sistema de governação sobremaneira complexo. Para Goss (2001): "a emergência das relações de governação tornam evidente que estamos numa era de legitimidades múltiplas, as quais todas são relevantes e importantes, fazendo, consequentemente, com que uma governação efectiva exija que todos os actores reconheçam a legitimidade uns dos outros, e que sejam capazes de negociar esta legitimidade partilhada de forma contínua" (p.23).

A questão da eficiência das decisões e das políticas públicas é igualmente importante, e levanta questões acerca de como controlar o uso de recursos por múltiplos actores de modo a funcionar eficientemente. Ser eficiente é, também, ser flexível de modo a produzir resultados tangíveis, maximizando os recursos. Isto implica a tendência para a proliferação de objectivos, critérios e indicadores face aos quais o funcionamento é avaliado, associando incentivos, recompensas e sanções a essa avaliação (PASTILLE 2002).

Adicionalmente, o próprio funcionamento democrático é posto em causa quando uma análise séria da governação para a sustentabilidade desafia as normas e os processos das democracias actuais (Lafferty 2004), particularmente quando os ciclos políticos são totalmente descoincidentes com os ciclos de vida ecológicos. No entanto, mesmo considerando

${ }^{1}$ Mais à frente abrevia-se a expressão 'governação para o desenvolvimento sustentável' para 'governação sustentável’, por uma questão meramente de simplificação linguística. 
que as redes de governação possibilitam o envolvimento de múltiplos actores, é evidente que uma participação alargada não equivale a um poder mais distribuído, e que a emergência do sistema de governação não significa, necessariamente, uma melhoria para a situação dos grupos sociais mais fracos. A participação é importante, mas está longe de ser suficiente (Meadowcroft 2004).

Por último, para Kjaer, a responsabilização implica responsabilidade; ser responsabilizável implica a possibilidade de se ser responsabilizado, e a teoria da governação preocupa-se com a definição de mecanismos de responsabilização democrática (Kjaer 2004). A capacidade de responsabilizar poderá simplesmente desaparecer ou diluir-se nas complexas redes de instituições, porque definir quem fez o quê, deixa de ser linear (Rhodes, citado por Kjaer 2004). Sempre contestada e em evolução, a intricada distribuição de autoridade e competências entre o Estado e os actores não-estatais ao nível local, regional, nacional e internacional, é um dos aspectos mais intrigantes da governação para o desenvolvimento sustentável (Fairbrass e Jordan 2004). Os diferentes níveis de acção implicam diferentes consequências para a responsabilização e para a democracia, sendo que é provavelmente no nível local, a uma escala de acção mais pequena, que encontraremos mais facilmente medidas que promovam uma capacidade de responsabilização mais efectiva. Paralelamente, o nível local será provavelmente aquele em que mais intensamente se tem tentado integrar políticas e práticas para a sustentabilidade, implementar diferentes modos de governação, e procurar respostas para os principais problemas e desafios da sustentabilidade. No entanto, a resolução eficaz de certos problemas, como, por exemplo, o aquecimento global ou a poluição transfronteiriça, transcendem claramente o nível local e o nacional.

Para Luhde-Thompson (2004, p.485), a arte de "governar cidades sustentáveis" pode definir-se pela "criação de governos locais competentes que, em interacção com uma sociedade civil altamente responsável e responsiva, aplicam uma forma de governar que possibilita as soluções mais sustentáveis". A questão que surge então é: Como podem esses governos locais competentes e uma sociedade civil consciente implementar políticas sustentáveis? Quais são as condições necessárias para que isso aconteça?

Vários estudos e análises comparativas no espaço Europeu (Lafferty 2001, PASTILLE 2002, Evans et tal. 2005, entre outros) têm procurado identificar e analisar os factores e condições que reforçam a capacidade da governação local para adoptar e desenvolver iniciativas que possibilitem um desenvolvimento sustentável. Partindo desses mesmos estudos, extraímos um conjunto de factores específicos que nos parecem pertinentes para uma implementação efectiva da Agenda Local 21 (AL21) (ver tabela 1). Esses factores foram agrupados segundo dois ângulos distintos: as condições geradas pelos "governos locais" e os factores gerados pela "sociedade civil" - aqui entendida como "todas as actividades sociais, económicas e políticas que têm lugar fora do governo local” (Evans et al. 2005, p. 14). Assume-se aqui que o nível do governo local - o foco do presente estudo - desempenha um papel importante na melhoria da governação para a sustentabilidade. Estando mais perto do território e da sua população, tem um acesso privilegiado aos problemas e conflitos ambientais, sociais e económicos, assim como à respectiva resolução dos mesmos. Tem também uma maior capacidade para conceber possíveis linhas de desenvolvimento que promovam os objectivos de sustentabilidade. Finalmente, a proximidade aos grupos de interesse (stakeholders) e ao público em geral poderá facilitar uma maior mobilização local para a criação conjunta de novas abordagens e parcerias. Os cinco factores aqui assumidos como cruciais estão resumidos na Tabela 1, reflectindo uma forma de reforçar este papel estratégico dos governos locais. 
Tabela 1 - Factores e condições determinantes para uma efectiva governação sustentável

\begin{tabular}{|c|c|}
\hline \multicolumn{2}{|l|}{ Governos Locais } \\
\hline Esforços de aprendizagem & - Habilidade/capacidade para desenvolver soluções inovadoras \\
\hline $\begin{array}{l}\text { Visão de longo prazo para o } \\
\text { desenvolvimento sustentável }\end{array}$ & $\begin{array}{l}\text { - Apoio a uma visão de longo prazo sem perder perspectiva sobre a acção a } \\
\text { curto e médio prazo } \\
\text { - Forte compromisso político para com os objectivos do desenvolvimento } \\
\text { sustentável }\end{array}$ \\
\hline $\begin{array}{l}\text { Parcerias/alianças com } \\
\text { indivíduos/organizações-chave } \\
\text { fora da esfera pública }\end{array}$ & $\begin{array}{l}\text { - Mecanismos que estabeleçam o acesso de diferentes grupos da sociedade } \\
\text { civil aos processos de tomada de decisão e de implementação }\end{array}$ \\
\hline $\begin{array}{l}\text { Interacção com actores } \\
\text { nacionais e internacionais }\end{array}$ & $\begin{array}{l}\text { - Desenvolvimento integrado de projectos/actividades/redes com outros níveis } \\
\text { de governo ou com organizações nacionais e internacionais para o } \\
\text { desenvolvimento sustentável }\end{array}$ \\
\hline $\begin{array}{l}\text { Condições internas e } \\
\text { organizacionais }\end{array}$ & $\begin{array}{l}\text { - Consciencialização/formação/educação dos funcionários públicos } \\
\text { relativamente ao desenvolvimento sustentável } \\
\text { - Organização interna/departamental que facilite a integração/avaliação/ } \\
\text { monitorização de politicas } \\
\text { - Estabelecimento de práticas de trabalho internas sustentáveis }\end{array}$ \\
\hline \multicolumn{2}{|l|}{ Sociedade Civil } \\
\hline $\begin{array}{l}\text { Consciencialização dos } \\
\text { desafios do Desenvolvimento } \\
\text { Sustentável }\end{array}$ & $\begin{array}{l}\text { - Nível de educação/consciência da população/sector privado/organizações } \\
\text { não-governamentais, etc }\end{array}$ \\
\hline Capacidade de Mobilização & $\begin{array}{l}\text { - Grau de actividade/mobilização/envolvimento da sociedade civil nos } \\
\text { assuntos públicos }\end{array}$ \\
\hline Confiança nas políticas locais & $\begin{array}{l}\text { - Grau de confiança nos governos e políticas locais. assim como no sector } \\
\text { público em geral }\end{array}$ \\
\hline $\begin{array}{l}\text { Cumprimento dos objectivos } \\
\text { ambientais }\end{array}$ & $\begin{array}{l}\text { - Nível de cumprimento com os objectivos ambientais e de sustentabilidade da } \\
\text { parte da população e do sector privado (consumo responsável, produção } \\
\text { responsável, etc) }\end{array}$ \\
\hline
\end{tabular}

Em primeiro lugar, de modo a ser o que designamos de organizações aprendentes, as autoridades locais necessitam ter a capacidade de desenvolver novas formas de funcionamento, que possibilitem processos de tomada de decisão mais abertos, inovadores e flexíveis, incorporando os objectivos inter-sectoriais e inter-geracionais do desenvolvimento sustentável. Kern (2008) tem argumentado por novos arranjos institucionais capazes de efectivamente aprender lições e transferir políticas; Evans e Theobald (2003), por seu lado, têm enfatizado a necessidade de criatividade, inovação e flexibilidade na criação de políticas, erodindo barreiras profissionais e departamentais; enquanto que outros autores sugerem aspectos como a descentralização, a construção de consensos e uma maior flexibilidade organizacional, enquanto aspectos que promovem sistemas políticos abertos e orientados para a aprendizagem. As AL21 são justamente uma oportunidade para introduzir estas mudanças e assim estimular o potencial de aprendizagem.

Um segundo factor diz respeito ao estabelecimento de uma visão de longo prazo para a sustentabilidade, sem perder a perspectiva de curto prazo da sua implementação. Particularmente no nível local, a existência de lideranças fortes e sólidas é extremamente importante para incluir aspectos de sustentabilidade na agenda política. No entanto, um compromisso político sólido necessita de ser acompanhado de mecanismos que apoiem a adopção e manutenção de programas e políticas integradas de longo prazo, o que se tem revelado um desafio difícil de superar, mesmo em países "pioneiros" na implementação da Agenda 21, como a Suécia, como veremos mais à frente.

Em terceiro lugar, se é imperativo forçar alterações concretas ao nível de padrões de consumo, de escolhas de transporte, de alteração de hábitos e preferências relativas a alimen- 
tação ou habitação, entre outros aspectos, os governos locais necessariamente devem interagir com organizações cívicas, empresas, comunidades, e com os cidadãos de um modo geral. Para além disso, a inclusão de novos actores possibilita um acréscimo de recursos disponíveis, não só em termos financeiros, mas também em termos de conhecimentos, habilitações, tempo, etc. Uma vez que os problemas financeiros são geralmente apontados como umas das causas principais para a falta de implementação da AL21, este aspecto é da maior importância. Contudo, como é evidente, proporcionar acesso aos processos decisórios e de implementação a diferentes grupos da sociedade civil é um princípio chave da AL21, o qual vai muito para além desta argumentação de acréscimo de "recursos".

O quarto factor, levantado pela natureza transversal do desenvolvimento sustentável, reflecte a forma como os governos locais interagem com os actores nacionais e internacionais. O desenvolvimento de projectos, de actividades e redes com os outros níveis do governo, ou com organizações nacionais ou internacionais envolvidas com a promoção do desenvolvimento sustentável através da AL21, é considerado crucial.

Finalmente, o quinto factor relaciona-se com as condições internas e organizacionais das autoridades locais, o que determina a forma como estas abraçam os desafios levantados pelos factores que temos mencionado. Estas condições implicam um grau adequado de formação, educação e saber técnico dos funcionários públicos e eleitos das administrações locais, particularmente em relação a questões de sustentabilidade (Evans et al. 2005). A forma como o governo local é estruturado para facilitar a integração de políticas - a importância relativa dos departamentos, como estes interagem, o grau de autonomia, e os recursos alocados pelos governos nacionais, etc. -, têm igualmente grande importância. Por fim, o estabelecimento de "boas" práticas de trabalho internas, como o Orçamento Ecológico (eco-Budget) ou as Compras Públicas Ecológicas (eco-Purchasing), poderá ter um efeito multiplicador fora da esfera das autoridades locais.

A próxima secção irá aprofundar de que forma a AL21 poderá promover os princípios fundamentais da governação para o desenvolvimento sustentável, substanciando esse potencial com as aprendizagens que a sua prática tem produzido e reunido até agora na Europa.

\section{0 Debate Internacional da Importância da Agenda Local 21}

A discussão académica e política em torno da intervenção local para o desenvolvimento sustentável tem contribuído para a elaboração de vários documentos, os quais têm dado especial importância a uma reformulação das administrações locais, de forma a melhorar a sua prestação. Entre estes documentos, destacamos o Capítulo 28 da Agenda 21 (1992), a Agenda Local 21 (AL21) propriamente dita, a Carta de Aalborg (1994) - a qual resultou da Campanha Europeia das Cidades e Vilas Sustentáveis-, e os mais recentes Compromissos de Aalborg (Aalborg + 10: Inspirando o Futuro - 2004). Essencialmente, a AL21 é um programa que fornece um quadro para a implementação do desenvolvimento sustentável ao nível local. Está concebido de forma a aproveitar os recursos e as estratégias previamente existentes dos governos locais, de forma a melhor integrar os objectivos ambientais, económicos e sociais.

Como mencionado na secção anterior, os conceitos-chave associados à governação como a sustentabilidade, a legitimidade, a eficiência de decisões e de políticas públicas, a 
democracia e a capacidade de responsabilização -, estão na base dos objectivos da AL21. Desde 1992, várias experiências locais têm sido desenvolvidas um pouco por todo o mundo, e muitas auditorias, questionários e relatórios têm sido preparados para avaliar as mudanças e desafios desses processos como, por ex., o Local Authorities Self Assessment of Local Agenda 21 Research Project (LASALA), com foco nos casos europeus (ver por ex. ICLEl 2000). De forma semelhante, têm sido feitos vários estudos sobre experiências ao nível regional (por ex. Adolfsson 2002, Barrutia et al. 2007) e nacional (por ex. O'Riordan and Voisey 1997, Laferty e Eckerberg 1997, Bond et al. 1998, Gram-Hansen 2000, Echebarria et al. 2004). 0 continente europeu tem sido portanto muito fértil relativamente à prática e ao savoir-faire produzido pela implementação de vários processos AL21. Não obstante, em países como a Suécia e o Reino Unido (R.U.), com longas e amplas experiências com a implementação da AL21, ou como a Alemanha, que aderiu tarde, mas que se tornou rapidamente um líder mundial em termos do número de processos iniciados (aproximadamente 2500 em 2004), observamos agora sinais de cansaço e de perda de interesse causados por vários anos de alterações e disputas em torno da AL21 (Wong 2006, Eckerberg e Dahlgren 2007, Kern et al. 2007). Eckerberg e Dahlgren (2007) anunciaram uma fase menos activa na Suécia, Kern et al. (2007) afirmaram peremptoriamente o fim do efeito de difusão desta inovação política na Alemanha, e no R.U., Wong (2006) enfatizou o facto de, ironicamente, os processos AL21 espontâneos terem perdido o seu impulso ao serem substituídos por "Estratégias Comunitárias" centralmente controladas.

0 interessante caso da Suécia justifica uma breve análise. Apesar do apoio maciço do governo central para a disseminação da AL21, e da devoção e capacidade dos municípios (através da autonomia local em competências políticas e fiscais), vários obstáculos têm causado um efeito "nebuloso" ao longo dos 15 anos de actividades AL21. Eckerberg e Dahlgren (2007) sugerem, curiosamente, que a falta de recursos tem-se revelado o obstáculo mais difícil para as autoridades locais. Mesmo depois de um forte apoio financeiro inicial, os fundos terminaram pois estavam associados a um projecto de curto-médio prazo. Contudo, foram ainda identificados como obstáculos importantes o carácter de curto prazo da tomada de decisão política local, e a consequente falta de compromisso a longo prazo. Os mesmos autores chamam também a atenção para o facto de o carácter voluntário da AL21 necessitar competir por recursos que são reivindicados por actividades municipais legalmente obrigatórias. Isto poderá explicar parcialmente as "soluções locais ad hoc" e as suas características de curto prazo. No que respeita o decréscimo de entusiasmo e a dificuldade em suster o compromisso político, estes autores explicam que isso estará provavelmente relacionado com a "integração iniciada mas não continuada da AL21 nas rotinas de trabalho e nos diferentes sectores que entram em conflito com outros pontos de vista temporais na política e na administração" (Eckerberg e Dahlgren 2007, p. 137). Os mesmos sublinham que a institucionalização da AL21 requer muito mais do que a mera produção e implementação de um plano de acção como um projecto de curto prazo.

Por toda a Europa, as várias experiências dizem-nos que o carácter voluntário e de curto prazo da AL21, assim como a falta da integração prática dos aspectos sociais, económicos e ambientais, são questões problemáticas. De forma a explorar o potencial da AL21, o ICLEI (2002) tem enfatizado a importância do desenvolvimento de mecanismos localmente relevantes para monitorizar e avaliar o progresso e a promoção de campanhas de AL21 de longo prazo ao nível nacional.

Estes dois aspectos foram alvo de atenção pelo governo central do R.U., quando através de imperativos legais e de um acompanhamento próximo, determinou a obrigatoriedade de cada administração local preparar uma "Estratégia Comunitária” (Community Strategy) 
através de uma Parceria Estratégica Local segundo o Local Government Act de 2000 (DETR 2000). Depois das várias experiências de AL21 nos anos 90, e de um forte apoio "retórico" da administração central, os vários obstáculos em torno da sua implementação começaram a tornar-se aparentes, notando-se cada vez mais a falta de recursos, o seu carácter nãoestatutário, as culturas políticas enraizadas das autoridades locais, a apatia do público e dos interesses privados, etc. (ver Jonas et al. 2004). A substituição de uma "AL21 ambiental" por "Estratégias Comunitárias integradas", pretendia levar os governos locais a ter de evidenciar, através de metas, planos de acção, e indicadores de "qualidade de vida", como estavam, em termos concretos, a contribuir para a dimensão ambiental do bem-estar e da qualidade de vida das suas comunidades (DETR 2000c, citado em Jonas et al. 2004). Além disso, pretendia também consolidar, através de orientação central, um enquadramento de política local em torno de várias iniciativas comuns que extravasavam a AL21, tais como planos de transporte público local, estratégias de combate ao crime e outros problemas locais, planos de melhoria no acesso aos serviços de saúde, e outros planos e estratégias locais de âmbito ambiental (Wong 2006). A AL21 no R.U., quando apareceu, oferecia oportunidades para a participação local, uma maior responsabilização democrática, assim como formas de contornar o governo central e participar directamente na governação ambiental transnacional, num contexto em que os poderes locais estavam a perder competências para o nível nacional e órgãos não imputáveis (ver Jonas et al. 2004). Presentemente, os dilemas da governação local criados pela fase actual de reestruturação do Estado e da economia, e das estratégias centrais para o nível local, estão a apresentar oportunidades para visões e estratégias alternativas para o desenvolvimento local e regional (Jonas et al. 2004).

As conclusões de Kern et al. (2007), sobre a exploração deste assunto na Alemanha, são significativas para a análise do caso português. Juntamente com a necessidade de apoio do governo central, estes autores identificam as capacidades económicas e políticas das autoridades locais como determinantes para a acção no âmbito da AL21. Concluem igualmente que existe uma maior probabilidade de a AL21 ser implementada por municípios de maior dimensão, em cidades mais densamente populadas, do que em pequenos municípios afastados das cidades pioneiras; que as cidades mais prósperas tendem a iniciar os processos de AL21 mais cedo devido à disponibilidade de recursos; que certos partidos políticos (em especial os de orientação ecologista) e os seus representantes na assembleia e no governo municipal tendem a mostrar-se mais favoráveis a iniciar uma AL21; e que a existência de capital social ${ }^{2}$ é uma pré-condição importante para a adopção de uma AL21. Um outro factor importante para a disseminação das mesmas, o qual é também significativo internacionalmente, é a existência de instituições de transferência de agendas ao nível regional (Kern et al. 2007). Estas instituições podem ser agências públicas ou privadas e que promovam e apoiem as autoridades locais na implementação da AL21, ajudando a difundir os respectivos processos.

Finalmente, é no caso dos países do Sul da Europa, tal como a Espanha, que podem ser encontradas características mais próximas às do contexto da AL21 em Portugal. De forma semelhante, o governo nacional espanhol não desempenhou um papel central, "deixando estas iniciativas nas mãos das autoridades regionais e locais" (Hanf e Morata 2008, p. 108). Os mesmos identificam os departamentos provinciais, tal como o Departamento de Ambiente do Generalitat de Catalunya (Governo da Região de Barcelona), enquanto agências

\footnotetext{
${ }^{2}$ Putnam, por exemplo, define capital social como as práticas sociais, normas e relações de confiança que existem entre cidadãos de uma dada sociedade e que estimulam a cooperação, coordenação e educação desses cidadãos para benefício da sociedade (Putnam, 1993 e 2000) (Ver discussão sobre o conceito de capital social e da sua importância para o desenvolvimento sustentável em Evans et tal. 2005, p. 14-20).
} 


\section{$\operatorname{RerCED\varrho ̈UA~}$}

Doutrina

ticas que se revelam cruciais para a promoção da AL21. Quando não existe este nível provincial, as experiências com a AL21 tendem a ser assimétricas e desarticuladas, e desencadeadas nesse caso por estratégias mais gerais de planeamento local. No entanto, a maior parte dos municípios em Espanha não parece entender a AL21 como um instrumento estratégico de planeamento que incorpora o conceito transversal de desenvolvimento sustentável, e a natureza fragmentada das organizações e do funcionamento das instituições administrativas locais em Espanha continua a representar um enorme entrave para a implementação da AL21 (Hanf e Morata 2008).

\section{A Agenda Local 21 em Portugal - Uma Visão Geral}

Relativamente à implementação da AL21 em Portugal, a prática revela um longo caminho a percorrer uma vez que, só muito recentemente, estas iniciativas começaram a assumir alguma expressão. Foi anteriormente mencionado que as campanhas nacionais para promover a adopção da Agenda Local 21 revelaram ser fundamentais. No entanto, os governos centrais Portugueses não têm atribuído muita relevância a estas estratégias locais. Nem os principais documentos estratégicos tal como o Plano Nacional da Política de Ambiente (1995), nem os sucessivos programas governamentais anuais, nem os principais documentos regulamentares como a Lei de Bases do Ordenamento do Território e Urbanismo e as respectivas regulações, incluíram referências ou incentivos para a adopção da AL21. Apesar de uma versão anterior (2002) ter mencionado a necessidade de promover a AL21 em Portugal, a actual Estratégia Nacional para o Desenvolvimento Sustentável 2007-2015 não refere em parte alguma objectivos ou medidas relacionadas com a AL21, e sequer refere o papel dos municípios enquanto actores indispensáveis para o desenvolvimento sustentável. 0 apoio político e financeiro dos governos centrais não foi, desta forma, um factor desencadeador do crescente número de experiências de Agendas 21 no nosso país, contrariamente ao que aconteceu no R.U., na Suécia, na Holanda ou em Itália, mas revela ser um dos factores que (pela sua inexistência) mais poderá ter contribuído para esse crescimento se desse tardiamente.

Entre os estudos que produziram dados sobre a implementação da AL21 em Portugal, três, em especial, ilustram bem a sua recente evolução. Em 2000, Carter et al. (2000) fazem referência a um questionário de 1997, que concluiu que o conhecimento da, e o entendimento sobre, a AL21 em Portugal era muito pobre, mencionando apenas quatro municípios que começavam a desenvolver uma AL21. Mais tarde, Quental e Silva (2003) referem-se a um inquérito realizado em 2002. Embora mostrassem resultados semelhantes (com apenas uma autarquia ${ }^{3}$ com uma AL21 em processo de implementação), revelavam uma crescente tomada de consciência e interesse sobre o assunto por parte dos municípios, assim como uma intenção crescente de as promover num futuro próximo. 0 inquérito revelava igualmente a existência de vários tipos de iniciativas dedicadas à gestão e ao planeamento ambiental, tal como a preparação de Planos Municipais de Ambiente em 20 autarquias, mas que todavia careciam de abordagens mais integradas e participativas. Um outro inquérito feito em 2002, constata a existência de 13 municípios com AL21 e de 23 com um Plano Municipal de Ambiente (ver Schmidt et al. 2005). Adicionalmente, de acordo com dados mais recentes, apenas dois municípios são membros do International Council for Local Environment Initiative (ICLEI) e 26 (mais a LIPOR - uma associação regional para a gestão de

\footnotetext{
3 Para o efeito deste artigo, importa salientar que nos referimos no texto a 'autarquias' ou 'municípios' da mesma forma, representando aqui o conceito de 'autarquia local' uma versão reduzida do seu significado, em que apenas nos queremos referir a câmaras municipais e não a freguesias locais, meramente por uma questão de simplificação terminológica que importava esclarecer.
} 
resíduos no norte de Portugal que integra oito municípios4) assinaram a Carta de Aalborg. Isto não significa, no entanto, que estes 26 municípios tenham necessariamente implementado planos de acção para o desenvolvimento sustentável, apenas que assumiram a responsabilidade de os desenvolver num futuro próximo. Destes 26 casos, a nossa recente investigação identificou 5 que tinham assinado a Carta de Aalborg há muito, mas que responderam ao nosso questionário como não tendo de todo uma AL21. Outros 10 declararam estar a implementar a AL21, e 11 autarquias signatárias não responderam ao questionário.

Vários obstáculos têm sido mencionados para explicar o baixo nível de adopção da AL21 em Portugal relativamente a outros países europeus (ver Schmidt et al. 2005). Uma dificuldade advém da falta de conhecimento sobre a AL21 e os desafios colocados pelo desenvolvimento sustentável por partes das autoridades municipais, o que realça a necessidade de campanhas ao nível nacional, como foi já referido. A própria Associação Nacional de Municípios Portugueses tem tido um papel limitado na promoção efectiva destas iniciativas. Um outro obstáculo está relacionado com a falta de apoio informativo e logístico de um ponto de vista técnico5. Além disso, a falta de recursos financeiros para apoiar as iniciativas relacionadas com a AL21 restringem as autarquias - as quais já têm, à partida, um orçamento limitado para lidar com todas as actividades reguladas pela lei -, de acumular encargos adicionais, principalmente se estes forem voluntários ${ }^{6}$. Por isso mesmo, o novo Quadro de Referência Estratégico Nacional (2007-2013) pode servir como um forte instrumento financeiro, ao incluir várias medidas sob as quais a promoção da AL21 em Portugal poderá ser apoiada, potenciador de novas iniciativas neste âmbito.

\section{A Agenda Local 21 em Portugal - Um Olhar Sobre a Prática}

\subsection{Questionário - Objectivos e Questões}

Os principais objectivos do questionário, desenvolvido pela Universidade de Aveiro, visavam, por um lado, fazer uma apreciação do grau de implementação da AL21 em Portugal, e, por outro, avaliar a forma como esta tem sido incorporada na gestão e planeamento ao nivel local. Sobretudo, pretendeu-se identificar os principais factores facilitadores e inibidores da implementação dos processos de AL21. Numa primeira fase, o questionário foi enviado, por correio, a todos os Presidentes de Câmara dos 308 municípios Portugueses, em Novembro de 2006. 0 reduzido número de respostas dos municípios dos arquipélagos da Madeira e dos Açores fez com que o estudo se reorientasse apenas para os municípios de Portugal continental (278). Numa fase seguinte, foram enviados questionários, por correio electrónico, em Maio de 2007 , para todos os municípios que não tinham respondido à primeira série. Esta estratégia possibilitou um número de respostas considerável de 158 municípios, representando cerca de $57 \%$ de todos os municípios do continente.

O questionário incluía um total de 19 questões fechadas, com várias categorias de respostas, das quais se geraram dados percentuais simples. Primeiramente, as questões pretendiam caracterizar os processos relativamente ao grau de implementação da AL21, as

\footnotetext{
4 LIPOR - Serviço Intermunicipalizado de Gestão de Resíduos do Grande Porto.

5 Mesmo assim, desde 2006, um sítio web foi criado pelo Grupo de Estudos Ambientais na Escola Superior de Biotecnologia da Universidade Católica do Porto, com o objectivo de ser uma ferramenta nacional para a partilha sistemática de informação e boas práticas relativamente às experiências com a AL21.

${ }^{6} \mathrm{O}$ orçamento nacional para 2005 previu, pela primeira vez, um fundo de $€ 150.000$ para a implementação da LA21. No entanto, este nunca chegou a ser usado após a mudança de governo resultante das eleições legislativas do mesmo ano, e os orçamentos posteriores de 2006, 2007 e 2008 confirmaram a ausência de apoio financeiro.
} 


\section{$\operatorname{RerCEDöUA~}$}

Doutrina

principais forças impulsionadoras por detrás desses esforços, assim como identificar os diferentes tipos de actores envolvidos nos processos. Um segundo grupo de questões procurava observar a capacidade de se integrar a dimensão ambiental nos objectivos socioeconómicos mais latos do desenvolvimento sustentável, e ver de que forma as estruturas dos governos locais facilitam a integração de políticas. Relativamente aos esforços de implementação, o nosso estudo procurou analisar, em particular, as parcerias estabelecidas e os mecanismos adoptados pelas Câmaras Municipais para promover o desenvolvimento sustentável. Por último, um conjunto final de questões destinava-se a examinar os mecanismos de avaliação e monitorização implementados ou previstos.

\subsection{Principais Resultados}

4.2.1. Um Bilhete de Identidade da AL21: número de processos e respectiva fase de implementação, nivel territorial e distribuição

Relativamente ao grau de implementação da AL21 em Portugal, os resultados obtidos com este questionário revelam uma situação bem diferente da avaliada em 2002 (ver Quental e Silva 2003), identificando 86 municípios envolvidos em processos de AL21 e 7 que adoptaram Planos Municipais de Ambiente, o que constituí uma evolução surpreendente para um período de apenas 5 anos. Tal como em Itália e Espanha (ver Sancassiani 2005; Hanf e Morata 2008), as Agendas 21 Portuguesas têm seguido um percurso contrário ao das tendências dos países dianteiros, crescendo fortemente em número apenas a partir de 2005 . As respostas mostram que a vasta maioria dos processos é muito recente: 63 foram iniciados depois de Janeiro de 2005; 24 entre 2002 e 2004; e apenas 6 terão sido iniciados antes de 2002. Como podemos observar na Fig. 1, a grande maioria não chegava ainda, à data, à fase de implementação do plano de acção. Embora muitos dos processos sejam recentes, uma percentagem considerável dos mesmos (11\%) está suspensa, não estando os processos a ser implementados.

\section{Figura 1 - Fases do processo de Agenda Local 21}

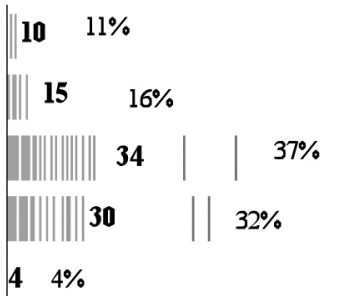

93

Entre os vários casos, encontramos 6 Agendas Regionais que estão a ser desenvolvidas através duma abordagem inter-municipal, envolvendo 47 municípios, num dos casos integrando mesmo municípios espanhóis (Eixo-Atlântico). Finalmente, e significativamente, a distribuição de processos AL21 parece não ter nenhum tipo de correlação com a localização em áreas onde as pressões ambientais são maiores. Contrariamente às conclusões de Kern et al. (2007), os resultados do questionário revelam que 51\% dos processos de AL21 são desenvolvidos em pequenos municípios com menos de 20,000 habitantes e distantes das cidades "pioneiras", e apenas $24 \%$ pelas autarquias mais populosas, com mais de 50,000 habitantes. Paralelamente, também não se constatou qualquer tipo de correlação entre a 


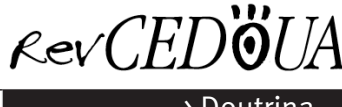

promoção dos processos AL21 e a orientação política das autarquias, sendo que tanto os partidos de direita como os de esquerda partilham um número semelhante de experiências.

\subsubsection{Forças impulsionadoras}

O principal ímpeto para desenvolver um processo de AL21, como vemos na Fig. 2, parece ter sido originado pela participação em redes internacionais e nacionais (60\% dos casos), prevalecendo claramente a influência nacional em detrimento da internacional. A principal explicação para este facto terá a ver com o crescente número de agendas regionais, e em particular através da influência das associações regionais de municípios enquanto instituições de transferência de agendas políticas, as quais têm constituído uma importante força impulsionadora para a promoção da AL21. Um aspecto menos positivo das respostas prende-se com a notória deficiência de intercâmbio de experiências ao nível internacional.

Figura 2 - Principal factor impulsionador da implementação de uma AL21

(eram possíveis múltiplas respostas)

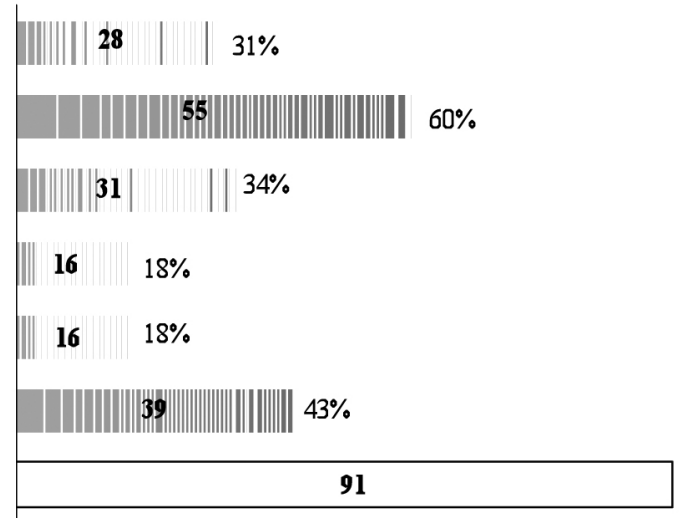

A importância do compromisso pessoal dos Presidentes das Câmaras para com a AL21 é também um factor impulsionador determinante ( $43 \%$ das respostas), que deve ser destacado. Outros tipos de motivações para a implementação da AL21 provieram do aconselhamento de especialistas ou de consequências visíveis de impactes ambientais locais negativos, ou, com menos peso, da pressão de pequenos grupos de interesse ou de exemplos de municípios vizinhos. Estes resultados são muito próximos daqueles referidos por Fidélis (2005).

\subsubsection{Envolvimento de Cidadãos e Grupos de Interesse}

0 envolvimento de cidadãos e de diferentes grupos de interesse nos processos AL21 é um princípio-chave consensual, e que reflecte a essência do conceito de acção conjunta para o desenvolvimento sustentável. Um primeiro grupo de questões pretendeu por isso mesmo, em primeiro lugar, avaliar o grau de envolvimento de equipas técnicas especializadas no desenvolvimento do processo. Uma parte relativamente significativa de processos estava a ser desenvolvida tecnicamente por empresas privadas de consultoria isoladamente $(21 \%)$ ou, em menor escala, por equipas universitárias (8\%). Isto indicia alguma falta de interacção entre os especialistas e os municípios, assim como uma definição pouco clara do papel da administração autárquica na formulação do processo. Ainda assim, a abordagem mais comum são equipas conjuntas entre municípios e universidades (41\%), ou empresas de consultoria (14\%), ou com ambos (13\%) (ver Fig. 3). Os dados, no seu conjunto, sublinham o facto de as Câmaras Municipais sentirem necessidades concretas de apoio técnico 
externo para conseguirem desenvolver os seus próprios processos, uma característica que tem sido indicada como comum nos países sul-europeus (ver Evans e Theobald 2003).

\section{Figura 3 - Responsabilidade técnica pelo processo de AL21}
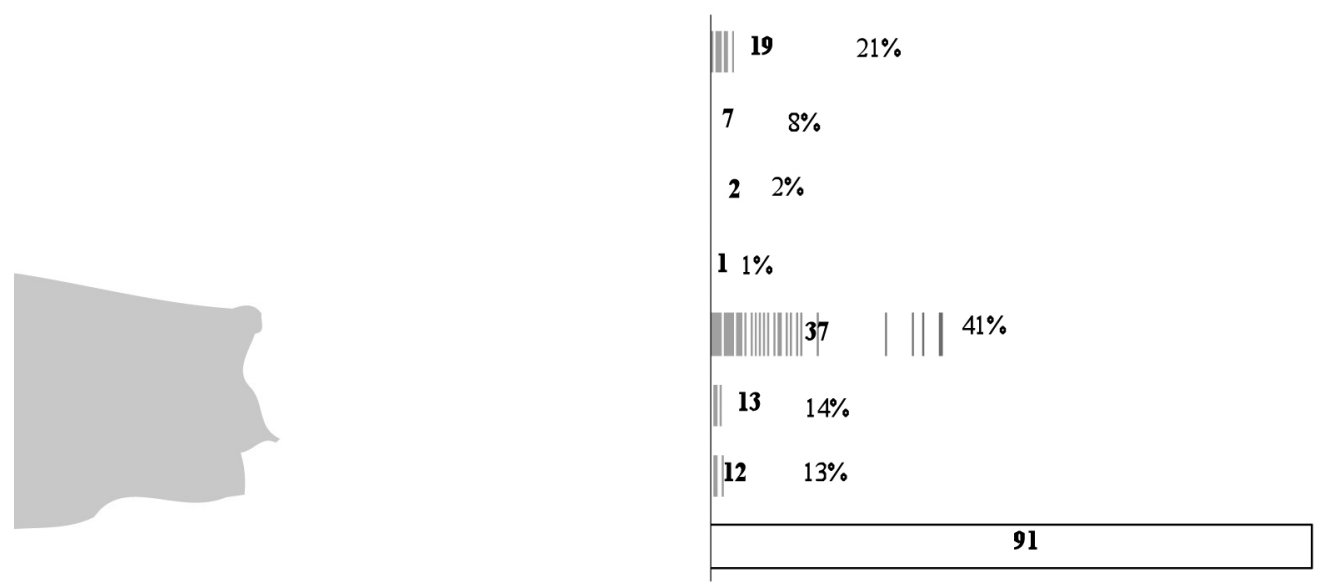

No que diz respeito à identificação dos principais grupos de interesse envolvidos no decorrer do processo, $46 \%$ dos municípios declararam que a população local foi amplamente envolvida no debate sobre a Agenda $21,33 \%$ indicaram que esta foi debatida por um grupo restrito de instituições e organizações locais, e em $21 \%$ dos casos, a discussão ocorreu envolveu tanto debates mais alargados como mais restritos (de um total de 66 respostas). Adicionalmente, 53 autarquias mencionaram ter já preparado um total de 128 workshops públicas durante o processo. Relativamente à tipologia dos grupos de interesse (ver Fig. 4), as respostas indicaram as escolas, empresas e juntas de freguesia como os actores dominantes, seguidos por ONGs ambientais, grupos culturais, grupos desportivos e recreativos, assembleias locais e universidades. Curiosamente, o governo central aparece em $49 \%$ das respostas como uma parte interessada no processo. Sendo de alguma forma surpreendente, este dado revela a necessidade de investigação adicional acerca deste aspecto. Uma leitura preliminar sugere uma imagem mais positiva da contribuição do governo nacional do que havia sido referido. Alguns cuidados devem, no entanto, estar presentes na leitura destes dados. Embora os municípios tenham referido vários grupos de interesse como altamente envolvidos no processo, existirá um risco considerável de se sobrestimar estes resultados. É importante mencionar que o grau de envolvimento (abordagens e estratégias participativas) não foi discriminado no questionário, e que portanto este poderá variar significativamente em função das circunstâncias locais, sendo também um aspecto que merece uma maior investigação. 
Figura 4 - Principais grupos de interesse envolvidos no processo de AL21 (eram possíveis múltiplas respostas)

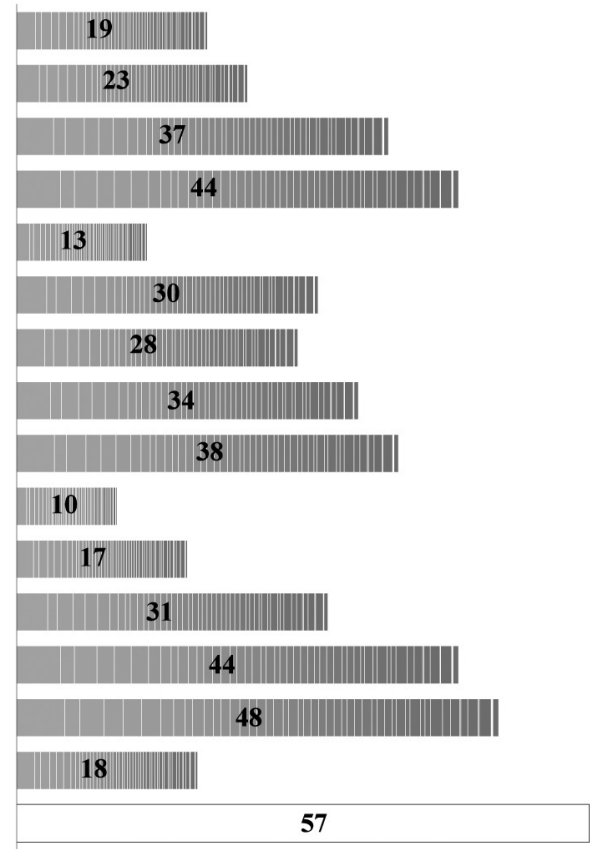

\subsection{4. Áreas de actuação e mecanismos de integração de políticas}

No que diz respeito às principais áreas de actuação da AL21, as mais citadas foram a gestão da água, os resíduos, o ordenamento do território, o ambiente urbano, os espaços verdes, a mobilidade/transportes, e a energia (Fig.5). Não sendo surpreendente, as questões que recebem menos atenção são aquelas associadas ao sector económico e ao de desenvolvimento social. 0 foco prende-se mais na resolução de graves problemas ambientais, do que em fazer uma análise do desenvolvimento económico e dos problemas sociais juntamente com a dimensão de sustentabilidade ambiental. Esta realidade retrata uma abordagem limitada e pouco integrada para com o conceito de desenvolvimento sustentável na prática, e revela que a AL21 em Portugal se depara com o mesmo tipo de limitações (e, consequentemente, com o mesmo tipo de críticas) que se tem observado na maioria das experiências europeias. 


\section{RerCEDöUA}

Figura 5 - Principais áreas abrangidas pela Agenda 21

(eram possíveis múltiplas respostas)
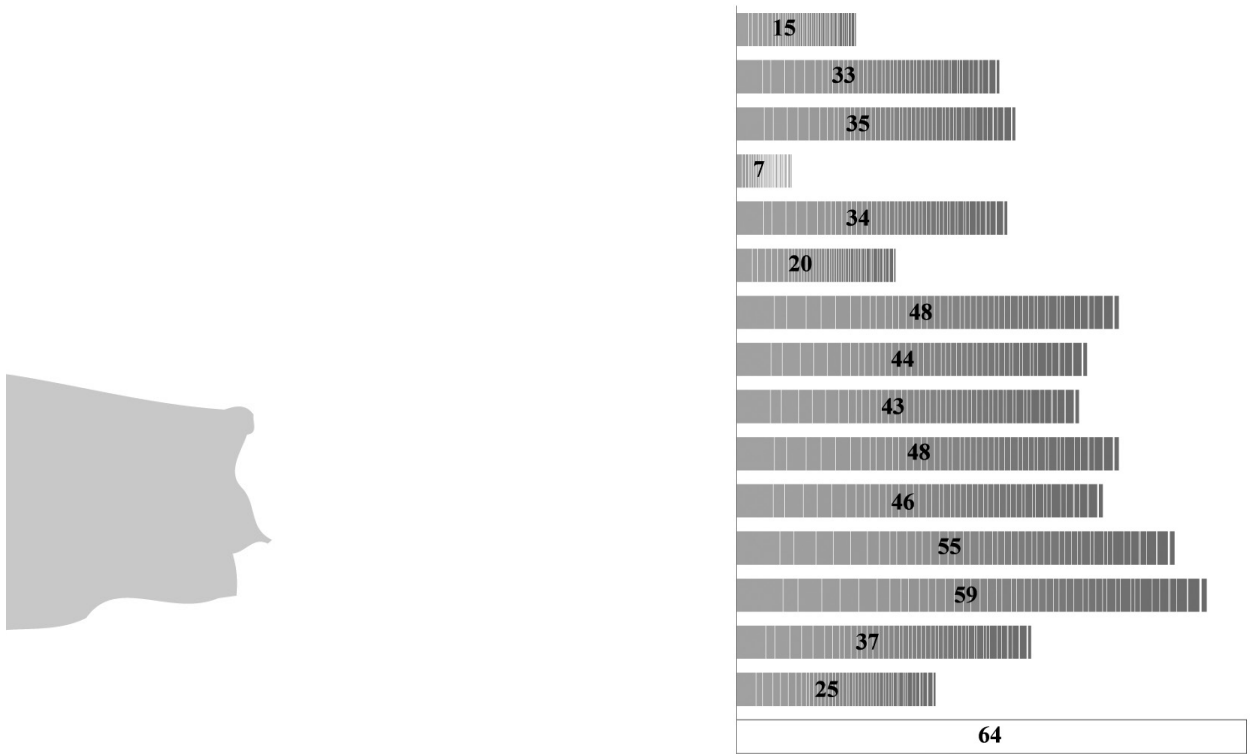

Em relação à identificação de mecanismos de integração de políticas (ver Fig. 6), constata-se que a maioria dos 34 municípios que responderam a esta questão detêm mecanismos para promover os fluxos de informação entre os departamentos (65\%) e têm grupos de trabalho com funcionários responsáveis pela AL21 e funcionários de diversos departamentos (56\%). Bem mais raras foram as referências a novas estratégias de trabalho mais integradas, tais como projectos interdepartamentais, ou trabalho conjunto de chefias de departamentos diferentes, o que poderia contribuir para um modelo de tomada de decisão menos compartimentado. Uma vez que a ausência de respostas foi muito maior para esta questão, assim como para as seguintes, podemos retirar daqui duas interpretações. Uma tem a ver com o facto de a generalidade dos processos estar ainda nas fases iniciais, sendo que a última parte do questionário se refere mais à fase de implementação. A segunda é menos evidente e optimista, e indica a falta de um real compromisso para com a AL21, - uma vez passadas as primeiras fases, o processo recebe muito menos atenção (e canaliza muito menos recursos), enfraquecendo a sua institucionalização efectiva no médio-longo prazo.

Figura 6 - Mecanismos de integração de políticas (eram possíveis múltiplas respostas)

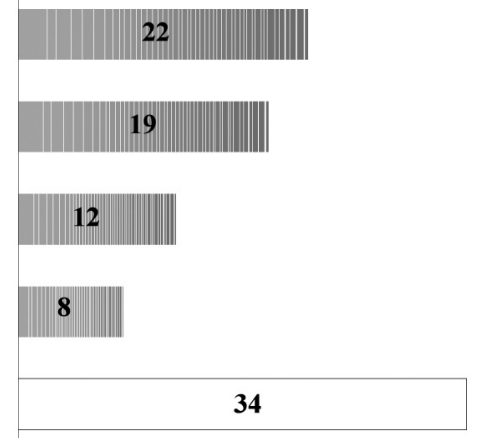




\subsubsection{A implementação do processo}

Relativamente ao estabelecimento de acordos para implementar o processo, das poucas autarquias que responderam (14\%), a maior parte estabeleceu parcerias com escolas e grupos locais. Algumas empresas privadas e organizações nacionais tiveram um envolvimento superficial, o que também foi o caso do governo nacional e de algumas empresas municipais (ver Fig. 7).

Figura 7 - Parcerias estabelecidas para a implementação do processo (eram possíveis múltiplas respostas)

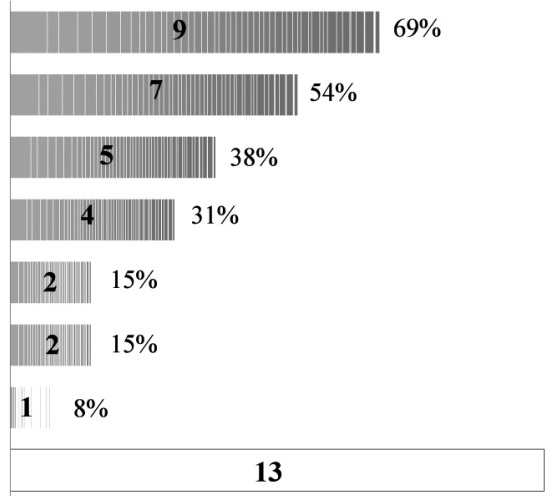

Relativamente aos mecanismos adoptados pelas autoridades municipais para promover o desenvolvimento sustentável, as respostas vão de encontro ao já mencionado (ver Fig. 8). Das 36 respostas, apenas $8 \%$ tinham criado um novo departamento na sua estrutura interna, $56 \%$ acrescentaram meramente novas responsabilidades a um departamento já existente, e $36 \%$ declararam ter adoptado outras soluções. Destes últimos, quase todos (64\% dos respondentes) estão envolvidos em agendas regionais, declarando existir de grupos de coordenação regionais; $18 \%$ afirmam ter distribuído novas competências por vários departamentos, enquanto que os outros $18 \%$ dizem ter novas equipas de trabalho.

\section{Figura 8 - Organização formal do processo dentro da Câmara Municipal}

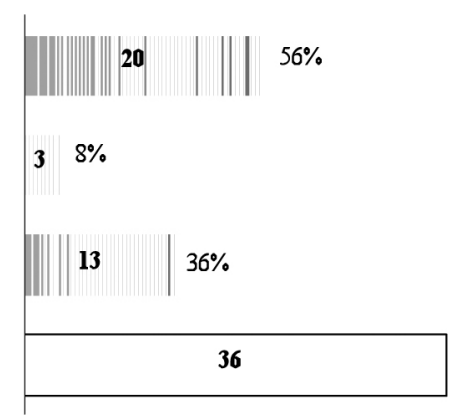

Quando questionados acerca de mecanismos para incorporar o contributo da AL21 na formulação das políticas e nos processos de tomada de decisão locais, as respostas foram igualmente escassas. Pouco mais de metade das respostas (57\%) afirmou ter mecanismos para promover a consulta dos grupos locais envolvidos na AL21 sempre que sejam tomadas decisões (Fig. 9). Apenas 37\% respondeu ter meios para reportar internamente o grau de sustentabilidade local na Câmara Municipal, e 23\% meios de comunicação/informação para reportar sobre o desenvolvimento sustentável entre a Câmara Municipal e outras organiza- 


\section{RerCEDöUA}

Doutrina

ções públicas locais. Uma minoria (11\%) refere ter mecanismos para apresentar e debater regularmente nas Assembleias Municipais a informação relevante para a sustentabilidade.

\section{Figura 9 - Mecanismos para incorporar as decisões da Agenda 21 na tomada de decisões locais (múltiplas respostas eram possíveis)}
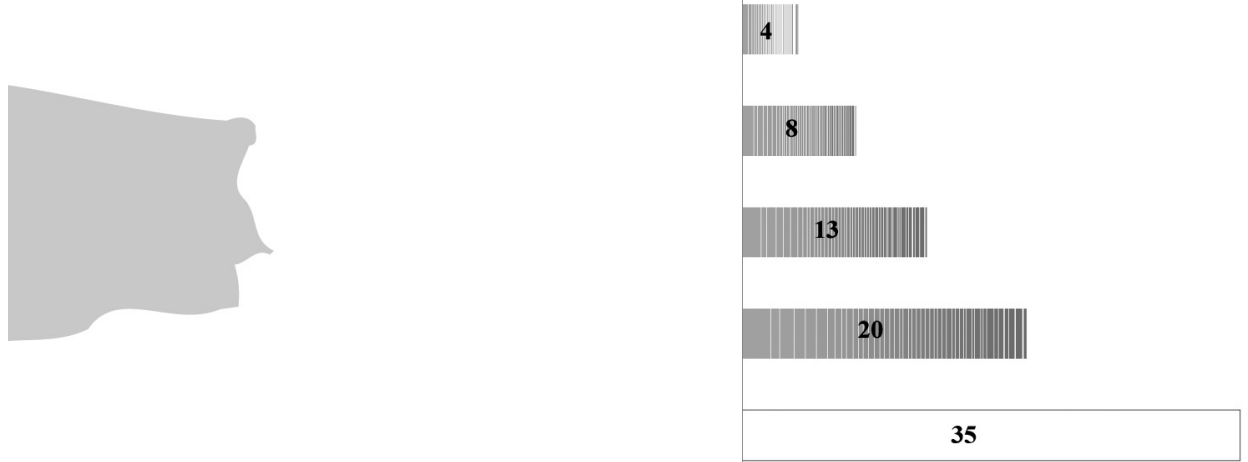

\subsubsection{Mecanismos de monitorização}

0 grupo final de questões focava o tipo de ferramentas de monitorização implementadas. A maior parte dos respondentes $(57 \%)$ declarou ter um conjunto de indicadores especificamente desenvolvidos para o processo, ou uma página de internet sobre a AL21 (36\%) (ver Fig. 10). As acções nas escolas foram também frequentemente mencionadas (32\%), embora esta ferramenta de "monitorização" tenha um efeito limitado. Algumas outras autarquias referem ter um observatório municipal ou outras ferramentas ( $7 \%$ e $2 \%$ respectivamente). Os resultados parecem menos positivos quando são consideradas as respostas acerca do tipo específico de indicadores de monitorização desenvolvidos: apenas 14 dos 21 municípios confirmaram o uso de indicadores desenhados localmente, e dois mencionaram a aplicação de indicadores europeus. Estas questões revelam assim uma fraca presença de mecanismos de monitorização.

Figura 10 - Mecanismos de monitorização previstos ou implementados (múltiplas respostas eram possíveis)

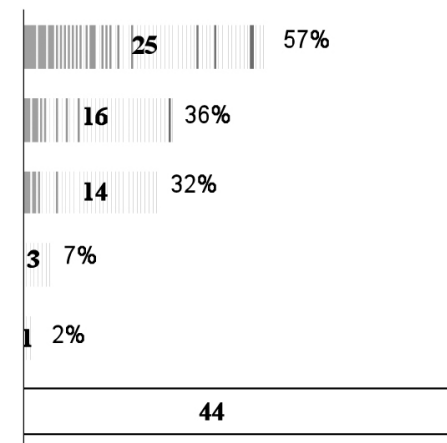




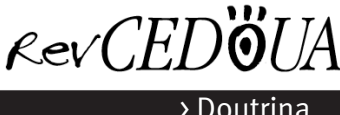

\section{Algumas reflexões sobre os resultados através da revisão de Literatura}

Partindo da revisão de literatura, valerá a pena interligar criticamente os factores para uma "boa" governação local sustentável com os resultados do questionário feito aos municípios portugueses - o grupo alvo e objecto de estudo deste artigo.

\subsection{Esforços de aprendizagem}

Uma reflexão preliminar do conjunto de dados demonstra que os esforços de aprendizagem e de inovação, muito embora sejam cruciais para a Agenda 21 e para o desenvolvimento sustentável em geral, ainda se encontram, na realidade local Portuguesa, numa fase prematura de governação local. Se é verdade que se observam alguns sinais positivos, estes tendem a prender-se com as fases iniciais do processo, isto é, com a discussão sobre o potencial e a relevância destes exercícios de planeamento do desenvolvimento sustentável, com a elaboração de diagnósticos locais, ou com a criatividade e diversidade de soluções e acções formuladas nos planos de acção. No entanto, e uma vez que se está numa fase inicial de implementação destes processos em Portugal, o potencial de aprendizagem ainda é muito grande.

\subsection{Visão de longo prazo}

Apesar de termos um contexto temporalmente muito reduzido para avaliar esta dimensão, uma visão de desenvolvimento sustentável de longo prazo parece estar pouco presente nos municípios portugueses que adoptaram Agendas 21. Apesar de assistirmos a um crescente número de processos, há, particularmente aqui, dois factores que limitam uma perspectiva actual de longo prazo. Um, prende-se com o facto de se verificar ainda um frágil investimento em parcerias para implementar as estratégias no longo prazo, assim como uma fraca adopção de mecanismos que permitam assegurar a sua monitorização e revisão. A isto acresce que, apesar de uma alta percentagem de processos adoptados como resultado do compromisso político dos presidentes de Câmaras Municipais, os vários casos de desistência de processos de AL21 após mudanças eleitorais testemunham a debilidade institucional da AL21, assim como a realidade desta não ter penetrado no substrato da administração municipal. Por outro lado, um outro factor prende-se com a fraca adopção de estratégias que integrem verdadeiramente o desenvolvimento económico com as dimensões sociais e ambientais, assim como a não consideração de cenários mais integrados de evolução futura. Podemos concluir que, pelo menos até agora, as AL21 não estão a contribuir para uma assimilação mais madura, ampla e de longo-prazo do conceito de desenvolvimento sustentável e das respectivas exigências administrativas.

\subsection{Participação e parcerias estabelecidas}

Em muitos dos processos de AL21 em Portugal, os níveis de participação da comunidade - geralmente alienados dos processos participativos convencionais como aqueles associados à aprovação dos planos territoriais ou aos procedimentos das avaliações de impacte ambiental (ver Vasconcelos 2001) - e de diferentes grupos de interesse foram mais elevados do que o habitual, particularmente nos municípios com baixa densidade populacional. A vontade das populações para participar ultrapassou as expectativas, contradizendo o lugar comum de os portugueses serem adversos a qualquer processo de participação pública. Contudo, tal como noutros países europeus, continuam a persistir problemas de representatividade democrática, claramente negligenciando alguns grupos de cidadãos em detrimento de outros. Para além disso, os líderes locais, quando confrontados com o facto de as discussões políticas proporcionadas pela AL21 poderem trazer desafios (in)oportunos às práticas instaladas de definição de políticas, prioridades e modelos de desenvolvimen- 
to, tenderão a sentir-se postos em causa na arena pública e, consequentemente, a restringir o seu envolvimento no processo, assim como a receptividade às propostas resultantes.

A partir do questionário, é difícil obter uma imagem autêntica do tipo e da 'força' das parcerias e alianças entre os governos locais e indivíduos e organizações-chave. Os resultados indicam uma presença promissora de vários grupos de interesse durante as primeiras fases de implementação, mas por outro lado, é desanimador ver o reduzido estabelecimento de parcerias para implementar as acções formuladas durante o processo. A maior parte da responsabilidade pela implementação tem recaído sobre (ou sido assumida por) as Câmaras Municipais, que não dispõem dos recursos técnicos e financeiros necessários.

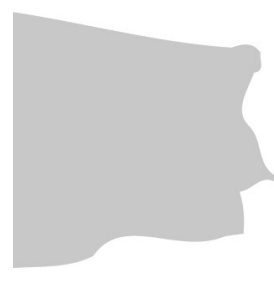

\subsection{Interacção com actores nacionais/internacionais}

Considerando os dados obtidos, constata-se que as ligações entre as Câmaras Municipais e redes nacionais ou internacionais associadas à AL21 ainda estão numa fase muito incipiente. A falta de apoio do governo central, e a necessidade de se racionalizar os esforços e recursos, explica talvez o surgimento do número considerável de agendas regionais. Desta forma, consideramos que o papel das associações regionais de municípios tem sido um factor crucial para explicar a disseminação da AL21 em Portugal. Estas associações regionais - ao facilitar o acesso a Fundos Comunitários para a concretização dos processos, ao promover a formação de funcionários envolvidos com AL21, ao fornecer um quadro estruturado para o seu desenvolvimento e implementação, sublinhando a necessidade de apoio a vários níveis, nomeadamente técnico e financeiro-, têm funcionado como instituições de transferência de conhecimento, possibilitando a criação de plataformas em que os municípios têm a oportunidade de interagir de forma estruturada e, sobretudo, mais informada.

Vale igualmente a pena mencionar a aparentemente fraca influência internacional, reflectida no número reduzido de municípios associados à Carta de Aalborg ou ao ICLEl. Exceptuando os poucos casos em que existem algumas relações com as autoridades locais espanholas, não parece existir grande interesse em aprender com as experiências de outros países no âmbito da AL21.

\subsection{Condições internas e organizacionais}

Finalmente, o que será provavelmente o factor mais crítico para o sucesso da governação local para o desenvolvimento sustentável em Portugal, reside nas estruturas internas do governo local, tanto culturais como organizacionais. Até agora, a AL21 não tem sido capaz de introduzir melhorias no funcionamento tradicional dos governos locais - caracterizados, entre outros aspectos, por uma acção compartimentada e isolada, com fracos fluxos de informação entre departamentos, e entre as próprias câmaras municipais e as respectivas comunidades, que não facilitam a identificação de prioridades e rumos de acção para um desenvolvimento local integrado. 0 questionário, assim como alguns casos de implementação que temos acompanhado, sugerem que muitas ideias e planos iniciais se perdem na arena de interesses e lobbies. A nossa revisão de literatura sugere que, neste panorama actual - sem instrumentos que exijam uma maior co-responsabilização e legitimidade democrática na definição de estratégias de desenvolvimento -, a promoção de novas práticas de ‘boa governação' não é garantida nem mesmo com o compromisso pessoal dos presidentes das câmaras que se verifica inicialmente. Com baixos níveis de responsabilização democrática e parcerias débeis, a eficácia dos processos poderá estar deteriorada à partida, o que fará com que seja difícil suster o compromisso político a longo prazo. 


\section{Conclusões}

Tal como os vários estudos comparativos sobre a AL21 na Europa têm indicado, a combinação de um forte apoio do governo central com a vontade política das autoridades locais é crucial para a sua evolução. Dada a falta de campanhas e apoio ao nível nacional, em Portugal a AL21 está genuinamente enraizada em iniciativas locais voluntárias, o que também faz com que tenham um carácter mais descoordenado. Curiosamente, verificamos que são especialmente os municípios mais pequenos - com menos população e pressões ambientais, e com mais fragilidades económico-sociais -, que mais aderem à AL21 em Portugal. Este aspecto contrasta claramente com as experiências dos países europeus mais ricos, onde as administrações centrais têm desempenhado um papel importante, e/ou os municípios têm mais recursos financeiros e competências políticas. Devido aos muitos obstáculos, algumas das experiências com a AL21 em Portugal revelam ser autênticas "caixas de Pandora”, revelando até que ponto a tomada de decisão local pode ser tão discricionária, ad-hoc, e vulnerável a interesses, e pouco aberta à discussão com os restantes membros da comunidade local.

Ao aprender a lidar com as vicissitudes da implementação da AL21, os processos desta poderão ser percepcionados pelas autoridades locais como oportunidades para reforçar e melhorar a governação local, em vez de meros obstáculos ao exercício do poder político. Em combinação, será importante investir mais no desenvolvimento de parcerias para a implementação de aç̧ões e projectos, assim como no funcionamento e integração inter-departamental dos municípios. Por último, chamamos a atenção para a necessidade premente de monitorizar e avaliar as sucessivas etapas da AL21 e sua respectiva eficácia, sendo para isso indispensável a criação de meios de recolha, análise e comunicação de informação ao nivel local.

Teresa Fidélis

Departamento de Ambiente e Ordenamento da Universidade de Aveiro

Sara Moreno Pires Faculdade de Direito da Universidade de Coimbra

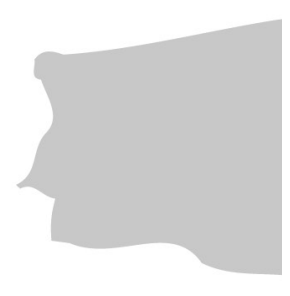

